\title{
Physician-diagnosed asthma and drug utilization in the European Community Respiratory Health Survey
}

\author{
C. Janson, S. Chinn, D. Jarvis, P. Burney \\ on behalf of the European Community Respiratory Health Survey
}

Physician-diagnosed asthma and drug utilization in the European Community Respiratory Health Survey. C. Janson, S. Chinn, D. Jarvis, P. Burney on behalf of the European Community Respiratory Health Survey. CERS Journals Ltd 1997.

ABSTRACT: The aim of this analysis was to estimate the geographical variation in the prevalence of physician-diagnosed asthma and treatment practice for asthma in young adults.

The results are based on an ecological analysis of 34 centres in 14 countries, in which a total of 17,029 randomly selected subjects (52\% females, age 20-48 yrs) underwent a structured interview and spirometry as part of the European Community Respiratory Health Survey. The sample was enriched with 2,903 symptomatic subjects when investigating treatment in subjects with physician-diagnosed asthma.

The prevalence of physician-diagnosed asthma was highest in New Zealand and Australia (11-13\%) and lowest in Erfurt, Germany (1.2\%) and Spain (1.5-3.0\%). The reported use of antiasthma medication in the last 12 months was also highest in New Zealand and Australia (12-16\%) and correlated closely with the prevalence of diagnosed asthma $(r=0.89, p<0.001)$. Herbal remedies against breathing problems had been used by $13 \%$ of subjects in Hamburg but the reported use of alternative remedies for breathing problems was low in most other centres. The use of inhaled anti-inflammatory drugs in subjects with physician-diagnosed asthma ranged from $49 \%$ in the UK to $17 \%$ in Italy and correlated with the prevalence of doctors' consultations within the last 12 months $(r=0.66, p<0.05)$. The prevalence of anti-inflammatory treatment was positively related to the prevalence of nocturnal asthma symptoms $(p<0.05)$.

We conclude that there is a wide geographical variation in the prevalence of physician-diagnosed asthma and use of antiasthma medication. The geographical variation in the use of anti-inflammatory drugs among individuals with diagnosed asthma may be related to variations in asthma severity, as well as differences in treatment practices between countries.

Eur Respir J 1997; 10: 1795-1802.

In the last decade there has been a move from oral to inhaled antiasthma treatment [1-3]. Audits of asthma care and analysis of drug sales indicate, however, that treatment practices for asthma vary considerably between countries [4-6]. In order to optimize the treatment for asthma, international guidelines for the management of asthma were produced in the 1990s. The guidelines emphasize that asthma is an inflammatory disease and that anti-inflammatory medication is a firstline treatment $[7,8]$.

Since 1990, information on the variation in asthma prevalence, known or suspected risk factors for atopy and asthma, and information on the management of asthma has been collected in the European Community Respiratory Health Survey (ECRHS) [9-11]. In the first part of the study, the participants answered a postal screening questionnaire that included questions on asthma-related symptoms and one question on whether the participants were currently taking medication for asthma. A considerable geographical variation in the prevalence of asthma symptoms and the reported use of asthma medication was found [10].
Dept of Public Health Medicine, United Medical and Dental Schools of Guy's and St Thomas' Hospitals, St Thomas' Hospital, London SE1 7EH, UK.

Correspondence: P. Burney

Dept of Public Health Medicine

United Medical and Dental Schools of Guy's and St Thomas' Hospitals

St Thomas' Hospital

London SE1 7EH

UK

Keywords: Alternative medicine asthma

beta -agonists $^{2}$

corticosteroids

drug utilization

prevalence

Received: September 131996

Accepted after revision April 301997
The aim of this analysis was to estimate the variation in the prevalence of physician-diagnosed asthma and treatment practice for asthma in the participating centres of the ECRHS.

Population and methods

\section{Selection of population}

The methods used in the study have been described previously [9-11]. Participating centres selected areas for study which were defined by pre-existing administrative boundaries, had populations of at least 150,000 inhabitants and, where possible, had up-to-date sampling frames for subjects aged 20-44 yrs.

Stage 1. In the first phase of the study, randomly selected samples of at least 1,500 people of each sex were sent questionnaires enquiring about respiratory symptoms, attacks of asthma, use of asthma medication and hay fever or nasal allergies, together with questions checking age and sex of the respondents. 
Stage 2. In the second part of the study, a random sample of those selected for the first stage were invited to come for a structured interview, blood test, skin tests and assessment of lung function by spirometry, and airway challenge with methacholine. Detailed information on medication used to help breathing and use of healthcare services because of breathing problems was collected during the interview. In many of the centres, an additional sample of all individuals who in the screening questionnaire reported: 1) having been woken by an attack of shortness of breath at any time in the last 12 months; 2) having an attack of asthma in the last 12 months; and/or 3) currently taking medicine for asthma, were invited to participate in the second stage of the study.

At the time of this analysis (March 1996) 48 centres from 22 countries had participated in the first phase of the study while 34 centres from 14 countries had completed the second phase and had their data checked by the co-ordinating centre. Enriched samples of symptomatic subjects had been included in 24 centres from 11 countries (table 1). The informed consent of all partic- ipants was obtained and the study was approved by all the Ethics Committees involved.

The random sample was used when comparing the overall prevalences of physician-diagnosed asthma and treatment for asthma by centre. The enriched sample was used when investigating the subsamples of subjects with physician-diagnosed asthma and subjects with asthma-related symptoms. In order to have a sufficient number of individuals for comparison, the data on subjects with physician-diagnosed asthma or asthma-related symptoms were analysed by country.

\section{Definitions}

Physician-diagnosed asthma was defined as reporting: 1) ever having had asthma where the diagnosis had been confirmed by a doctor; and 2) having at least one asthma-related symptom in the last 12 months.

A subject was considered to have asthma-related symptoms if he or she reported at least one of the following: 1) wheezing or whistling in the chest; 2) having been woken with a feeling of tightness in the chest; 3) having had an attack of shortness of breath during the day at rest; 4) having had an attack of shortness of breath following strenuous activity; or 5) having been woken by an attack of shortness of breath in the last 12 months. Inhaled bronchodilators included: 1) beta $_{2}$-agonist; 2) nonspecific adrenoreceptor agonists; 3 ) anticholinergic agents; and 4) compound bronchodilators.

Inhaled anti-inflammatory medication included: 1) inhaled steroids; 2) sodium cromoglycate and nedocromil sodium; and 3) compound bronchodilators containing steroids or sodium cromoglycate.

Oral antiasthma medication included: 1) beta $_{2}$-agonist; 2) theophylline; 3 ) ketotifen; 4) compound bronchodilators; and 5 ) oral corticosteroids taken because of breathing problems.

The subjects were also asked whether they had used any remedies (other than drug treatment) for breathing problems in the last 12 months. The remedies reported included: hypnotherapy; acupuncture; homeopathy or herbal remedies; diet control; breathing exercises; swimming or other exercises; and reflexology.

\section{Statistical analysis}

The statistical analysis was performed using Statistical Analysis System (SAS) (SAS Institute Inc, Cary, NC, USA) and Generalized Linear Interactive Modelling (GLIM) software [12]. Linear regression was used when correlating the prevalence of physician-diagnosed asthma with the prevalence of antiasthma 
DRUG UTILIZATION IN THE ECRHS

medication between centres and when comparing the prevalence of antiasthma treatment with doctor consultations and asthma severity in subjects with physician-diagnosed asthma between countries. Logistic regression was used when calculating odds ratios for the influence of age and sex on the prevalence of diagnosed asthma and antiasthma medication. Logistic regression was also used when analysing variation in antiasthma medication in subjects with diagnosed asthma and asthma-related symptoms by country after adjustment for age and sex.

Adjusted prevalences of physiciandiagnosed asthma and antiasthma medication were calculated by taking account of the nonparticipation rate and the characteristics of the nonrespondents in stage 2 . The age, sex and symptomatology of the responders and nonresponders were known from the screening questionnaire in stage 1 and the adjusted prevalence estimate made the assumption that the nonresponders had the same prevalence of diagnosed asthma and antiasthma medication as responders of the same sex and age group, living in the same centre with the same symptoms reported in the screening questionnaire [11].

\section{Results}

The total number of participants in the random sample was 17,029 (52.2\% female, mean age 33.8 yrs, range $20-48$ yrs). The participation rate varied from $90 \%$ in Umeå to $12 \%$ in Montpellier. The total number of participants in the symptomatic sample was 2,903 (56.7\% female, mean age $34.1 \mathrm{yrs}$, range $20-47 \mathrm{yrs}$ ) (table $1)$.

\section{Participants and nonparticipants}

Women were more likely than men to participate in the second phase of the study and participation increased with age. In many centres, participants had a higher prevalence of wheeze, reported attacks of asthma and current medication for asthma in stage 1 than nonparticipants (table 2).

\section{Physician-diagnosed asthma and antiasthma treatment}

High prevalences of physician-diagnosed asthma, i.e. with a lower 95\% confidence limit above and excluding the median (5.3\%), were found in Bordeaux, Montpellier, Paris, Portland, Melbourne and all centres in the UK and New Zealand. Low prevalences of physician-diagnosed asthma, i.e. with an upper $95 \%$ confidence level below and excluding the median were found in South Antwerp, Bergen-op-Zoom, Geleen, Reykjavik, Erfurt and all the centres in Spain. $(\mathrm{N})$ in stage 2

\begin{tabular}{|c|c|c|c|c|c|c|}
\hline \multirow[t]{2}{*}{ Centre } & \multicolumn{2}{|c|}{ Wheeze } & \multicolumn{2}{|c|}{ Attacks of asthma } & \multicolumn{2}{|c|}{$\begin{array}{l}\text { Medication for } \\
\text { asthma }\end{array}$} \\
\hline & $\mathrm{P}$ & $\mathrm{N}$ & $\mathrm{P}$ & $\mathrm{N}$ & $\mathrm{P}$ & $\mathrm{N}$ \\
\hline Reykjavik & 19.2 & $10.4^{*}$ & 2.5 & 2.8 & 2.5 & 2.8 \\
\hline Bergen & 23.6 & 22.6 & 2.8 & 3.2 & 3.3 & 2.5 \\
\hline Göteborg & 23.3 & 21.2 & 3.0 & 4.5 & 4.7 & 7.8 \\
\hline Umeå & 19.9 & $8.5 *$ & 2.0 & 3.4 & 6.9 & 3.4 \\
\hline Uppsala & 19.4 & 20.9 & 3.6 & 4.6 & 6.3 & 5.8 \\
\hline Dublin & 31.5 & 27.5 & 4.4 & 2.8 & 4.9 & 2.8 \\
\hline Cambridge & 28.6 & 26.0 & 5.8 & 7.6 & 6.9 & 8.5 \\
\hline Caerphilly & 34.0 & 33.1 & 6.6 & 4.6 & 6.9 & 7.3 \\
\hline Ipswich & 27.2 & $19.0 *$ & 5.8 & 4.3 & 8.3 & 6.0 \\
\hline Norwich & 27.1 & 20.4 & 4.7 & 5.0 & 6.1 & 5.0 \\
\hline Hamburg & 23.9 & $19.1 * * *$ & 3.5 & 2.6 & 4.1 & 2.9 \\
\hline Erfurt & 9.8 & 13.7 & 1.1 & 1.4 & 0.7 & 1.2 \\
\hline Groningen & 18.2 & 18.3 & 3.2 & 1.4 & 3.7 & 2.3 \\
\hline Bergen-op-Zoom & 18.9 & 13.0 & 3.1 & 2.7 & 4.9 & 3.8 \\
\hline Geleen & 18.8 & 18.5 & 1.5 & 3.4 & 3.9 & 4.7 \\
\hline South Antwerp & 14.2 & 11.6 & 1.6 & $0^{*}$ & 2.5 & 2.1 \\
\hline Antwerp City & 25.9 & $19.5^{*}$ & 4.1 & 3.0 & 4.3 & 2.6 \\
\hline Bordeaux & 23.8 & $14.2 * * *$ & 10.7 & $3.3 * * *$ & 7.7 & $3.0 * * *$ \\
\hline Grenoble & 16.0 & 12.0 & 3.8 & 2.3 & 2.6 & 1.6 \\
\hline Montpellier & 22.4 & $12.9 * * *$ & 7.5 & $3.0 * * *$ & 8.6 & $2.7 * * *$ \\
\hline Paris & 18.4 & $13.2 * * *$ & 5.7 & $3.6^{*}$ & 4.8 & 2.6 \\
\hline Barcelona & 17.3 & 19.2 & 1.3 & 1.4 & 1.8 & 1.4 \\
\hline Galdakao & 20.0 & 12.2 & 1.6 & 1.1 & 1.4 & 1.1 \\
\hline Albacete & 28.0 & $18.4 * *$ & 3.9 & 1.4 & 2.1 & 2.2 \\
\hline Oviedo & 23.2 & $12.7 * * *$ & 2.8 & 0.6 & 2.8 & 0.6 \\
\hline Huelva & 30.4 & 27.2 & 2.6 & 1.4 & 5.2 & $1.5^{*}$ \\
\hline Pavia & 12.6 & $6.4 * *$ & 2.3 & 2.8 & 2.3 & 0.8 \\
\hline Turin & 15.6 & $8.4^{*}$ & 7.0 & 3.3 & 3.3 & 2.6 \\
\hline Verona & 11.8 & $4.3 * *$ & 4.4 & 3.1 & 2.1 & 1.2 \\
\hline Portland & 26.7 & 23.7 & 6.8 & 4.7 & 4.4 & 4.9 \\
\hline Wellington & 26.0 & 26.2 & 7.6 & 5.9 & 9.3 & 6.6 \\
\hline Christchurch & 25.1 & 24.8 & 7.8 & 7.5 & 8.5 & 7.1 \\
\hline Hawkes Bay & 27.8 & $18.9 *$ & 6.3 & 3.4 & 6.6 & 5.2 \\
\hline Melbourne & 30.0 & $18.3 * * *$ & 5.5 & $3.0 *$ & 6.0 & $3.0 * *$ \\
\hline
\end{tabular}
not age and sex adjusted as in [10]. *: $\mathrm{p}<0.05 ; * *$ : $\mathrm{p}<0.01 ; * * *$ : $\mathrm{p}<0.001$ for difference between participants and nonparticipants.

Prevalences of antiasthma medication significantly above the median $(6.7 \%)$ were found in Bordeaux, Montpellier, Grenoble, Caerphilly, Ipswich, Norwich, Umeå, Portland, Melbourne and the centres in New Zealand. Prevalences of antiasthma medication significantly below the median were found in Barcelona, Galdakao, Oviedo, Geleen, Hamburg, Erfurt, Reykjavik and Bergen.

The adjusted prevalences of physician-diagnosed asthma and antiasthma treatment are presented in figure 1 and table 3. In most centres, adjustment for nonparticipation reduced the prevalence of physician-diagnosed asthma and reported use of antiasthma medication. In the majority of centres, the adjustment changed the estimated prevalence by less than $20 \%$ of the unadjusted value. The largest reduction in the estimated prevalence of physician-diagnosed asthma was found in Bordeaux where the estimate fell from 15.1 to $8.8 \%$. An adjustment in prevalence of more than $20 \%$ was also found in Montpellier (13.8 to $10.1 \%$ ), Portland (10.4 to $7.9 \%$ ), Turin $(7.4$ to $5.8 \%)$ and Verona (5.6 to $4.4 \%)$. A reduction in the estimated prevalence of use of antiasthma 
Physician-diagnosed asthma Antiasthma medication

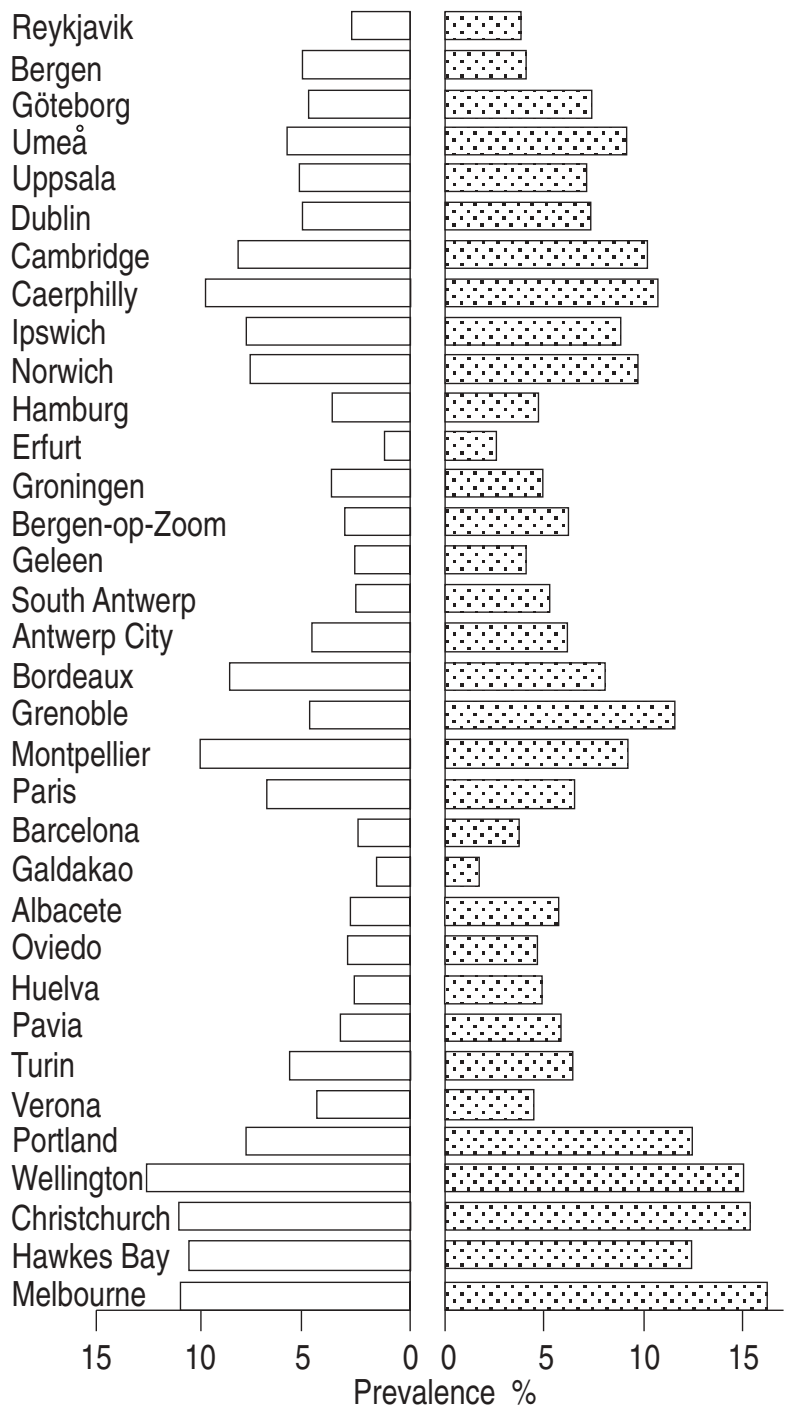

Fig. 1. - Age-sex standardized prevalence of physician-diagnosed asthma and antiasthma medication, adjusted for nonparticipation.

medication of more than $20 \%$ was found in Bordeaux (13.1 to $7.6 \%$ ) and Montpellier (12.5 to $8.8 \%$ ). A highly significant across centre correlation was found between the adjusted prevalences of physician-diagnosed asthma and antiasthma medication $(\mathrm{r}=0.89, \mathrm{p}<0.001)$ (fig 2).

Asthma and medication in relation to gender and age

In most centres, no significant age or sex difference was found relating to physician-diagnosed asthma or reported use of antiasthma medication. One exception was Uppsala where there was a significantly higher prevalence of physician-diagnosed asthma in women than men (odds ratio (OR) (95\% confidence interval) 3.8 (1.68.8)). A significantly higher reported use of antiasthma medication in women than men was found in Groningen (3.3 (1.1-10.2)) and in Grenoble (1.8 (1.0-3.2)) while in Antwerp City the reported use of medication was higher in men than in women $(2.1(1.0-4.4))$. A significantly lower prevalence of physician-diagnosed asthma with higher age (OR 10 yrs) was found in Ipswich
Table 3. - Age and sex standardized prevalence of antiasthma medication, adjusted for nonparticipation

\begin{tabular}{|c|c|c|c|}
\hline Centre & $\begin{array}{c}\text { Inhaled } \\
\text { broncho- } \\
\text { dilators } \\
\%\end{array}$ & $\begin{array}{c}\text { Inhaled } \\
\text { anti- } \\
\text { inflammatory } \\
\%\end{array}$ & $\begin{array}{c}\text { Oral } \\
\text { anti- } \\
\text { asthma } \\
\%\end{array}$ \\
\hline Reykjavik & $2.5^{\#}$ & $1.0^{\#}$ & $0.5^{\#}$ \\
\hline Bergen & 3.4 & $1.4^{\#}$ & $0.5^{\#}$ \\
\hline Göteborg & 6.3 & 1.7 & 1.7 \\
\hline Umeå & 8.0 & 2.3 & $1.4^{\#}$ \\
\hline Uppsala & 5.8 & $1.9^{\#}$ & $1.4^{\#}$ \\
\hline Dublin & 4.3 & 2.8 & 2.9 \\
\hline Cambridge & 9.2 & 6.5 & $1.6^{\#}$ \\
\hline Caerphilly & 8.0 & 4.4 & $2.1^{\#}$ \\
\hline Ipswich & 7.6 & 3.8 & $1.9^{\#}$ \\
\hline Norwich & 8.7 & 3.0 & $1.5^{\#}$ \\
\hline Hamburg & 4.1 & 1.1 & 1.2 \\
\hline Erfurt & $1.0^{\#}$ & $0.3^{\#}$ & $0.9^{\#}$ \\
\hline Groningen & 3.4 & $1.5^{\#}$ & $0.8^{\#}$ \\
\hline Bergen-op-Zoom & 4.7 & $2.5^{\#}$ & $0.9^{\#}$ \\
\hline Geleen & 2.9 & $1.2^{\#}$ & $0.4^{\#}$ \\
\hline South Antwerp & 4.5 & $1.6^{\#}$ & $1.1^{\#}$ \\
\hline Antwerp City & 5.2 & $2.6^{\#}$ & $1.2^{\#}$ \\
\hline Bordeaux & 5.1 & 3.2 & 2.8 \\
\hline Grenoble & 3.6 & 3.2 & 6.5 \\
\hline Montpellier & 5.4 & 3.4 & 3.0 \\
\hline Paris & 5.0 & 1.4 & 1.8 \\
\hline Barcelona & $1.1^{\#}$ & $1.2^{\#}$ & $1.6^{\#}$ \\
\hline Galdakao & $0.7^{\#}$ & $0.8^{\#}$ & $0.2^{\#}$ \\
\hline Albacete & 2.8 & 3.1 & $0.8^{\#}$ \\
\hline Oviedo & $1.6^{\#}$ & $2.3^{\#}$ & $2.3^{\#}$ \\
\hline Huelva & $2.3^{\#}$ & 2.9 & 1.6 \\
\hline Pavia & 3.4 & 2.9 & $0.8^{\#}$ \\
\hline Turin & 2.8 & 2.8 & $1.5^{\#}$ \\
\hline Verona & $1.9^{\#}$ & $2.7^{\#}$ & $1.2^{\#}$ \\
\hline Portland & 6.1 & 6.7 & $0.8^{\#}$ \\
\hline Wellington & 11.3 & 8.2 & $2.0^{\#}$ \\
\hline Christchurch & 12.4 & 6.9 & 3.5 \\
\hline Hawkes Bay & 8.9 & 7.7 & 2.4 \\
\hline Melbourne & 9.4 & 6.7 & 5.0 \\
\hline
\end{tabular}

\#: Adjustment for nonparticipation not possible due to low prevalence rates

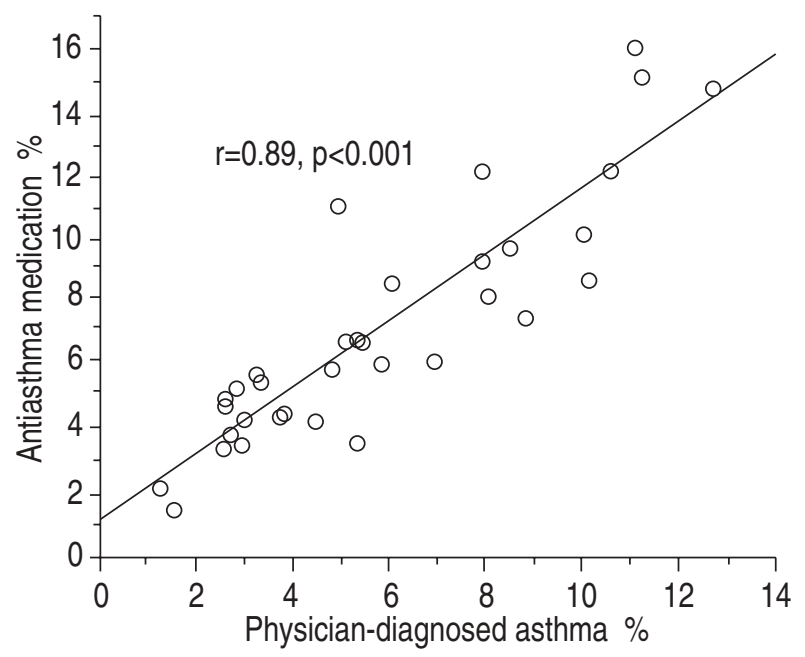

Fig. 2. - Correlation between the adjusted prevalence of physiciandiagnosed asthma and antiasthma medication in each centre.

(0.5 (0.2-0.9)), Montpellier (0.6 (0.4-0.8)) and Bordeaux $(0.7(0.5-0.9))$. A higher reported use of antiasthma medication with increasing age was found in Reykjavik 
(2.1 (1.0-4.4)) and Bergen (1.9 (1.1-3.5)), while a lower reported use of medication with increasing age was found in Galdakao (0.3 (0.1-1.0)) and Uppsala (0.6 $(0.3-0.9))$. As 136 tests were performed in this analysis, the number of statistically significant associations found were about as many as could be randomly expected.

\section{Alternative remedies}

The prevalence of use of alternative remedies for breathing problems was low in most centres. The most commonly reported alternative remedy against breathing problems was homeopathy or other herbal remedies which had been used by $13.4 \%$ of the individuals from Hamburg. Prevalences above $2 \%$ for herbal remedies were also reported in Grenoble (7.8\%), Erfurt (3.2\%), Bordeaux (2.9\%) and Dublin $(2.3 \%)$. A prevalence above $1 \%$ for acupuncture against breathing problems was only reported in Bordeaux $(1.3 \%)$. Very few subjects reported having used hypnotherapy, diet control, breathing exercises, swimming or other exercises, or reflexology against breathing problems in the previous 12 months.

\section{Medication in subjects with physician-diagnosed asthma}

In the whole population, $58 \%$ of those who had used antiasthma medication in the last year had physiciandiagnosed asthma. Prevalences of reported use of antiasthma medication in subjects with physician-diagnosed asthma are presented in table 4 and figure 3. Significant geographical variation was found $(\mathrm{p}<0.001)$, with the highest prevalence of use of antiasthma medication in the UK and Sweden and the lowest in Italy and Norway (table 4). There was a wide variation in the use of inhaled anti-inflammatory medication in the last 12 months with the highest prevalences found in the UK (49\%) and New Zealand (47\%), while the lowest prevalences were seen in France $(20 \%)$ and Italy (17\%) (fig. $3)$. The highest prevalences of daily inhaled anti-inflammatory medication were found in New Zealand (29\%) and the UK (27\%), while the lowest prevalence was found in the USA (5\%) and Italy (0\%). The highest use of inhaled bronchodilators in the last 12 months was found in Sweden (82\%), New Zealand $(80 \%)$ and the UK $(80 \%)$, while the lowest prevalence was seen in Spain $(53 \%)$ and Norway $(45 \%)$. The geographical variations in the prevalences of use of inhaled medication were all statistically significant $(\mathrm{p}<0.001)$.

A significant correlation was found between the reported use of inhaled bronchodilator and inhaled antiinflammatory treatment in the last 12 months $(r=0.78$, $\mathrm{p}<0.001)$. There was also a significant correlation between daily use of inhaled bronchodilators and daily inhaled anti-inflammatory treatment $(\mathrm{r}=0.54, \mathrm{p}<0.05)$.

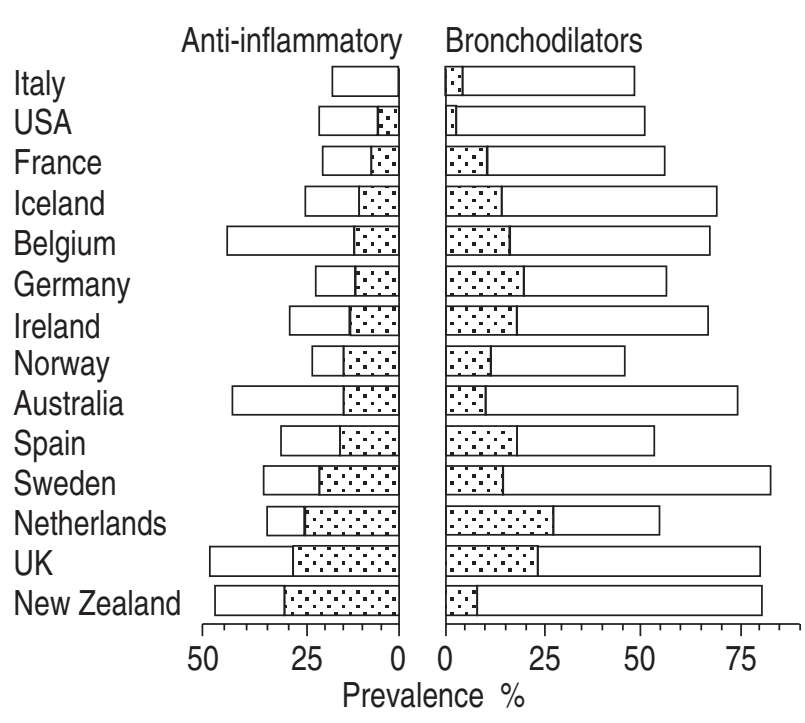

Fig. 3. - Prevalence of inhaled bronchodilators and inhaled antiinflammatory medication in subjects with physician-diagnosed asthma. The countries are sorted by the prevalence of daily use of anti-inflammatory medication. $\square$ : daily medication; $\square$ : medication in the last 12 months.

When studying the pattern of inhaled and oral medication in subjects with diagnosed asthma, the highest

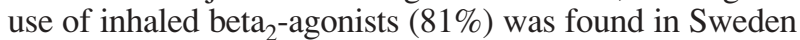
and the highest reported use of inhaled steroids (46\%) in New Zealand. The highest use of inhaled anticholinergics $(6 \%)$ and cromoglycate $(13 \%)$ was reported in Belgium. Inhaled compound bronchodilators were predominantly used in Germany (29\%), Italy (13\%) and Belgium (13\%). The highest prevalence of the use of oral beta ${ }_{2}$-agonists $(13 \%)$ was reported in Sweden, the highest use of theophylline (17\%) was found in Belgium, while the highest use of oral corticosteroids (13\%) was reported in Ireland and New Zealand. Ketotifen was mainly used in Belgium (6\%) and Spain (5\%). The highest reported use of alternative remedies was found in Germany and Belgium (table 4).

The highest proportion of asthmatics that had seen a doctor in the last 12 months was found in Belgium $(60 \%)$, while in most of the other countries this was 
Table 5. - Doctor consultations and asthma severity in subjects with physician-diagnosed asthma (\%)

\begin{tabular}{lccccc}
\hline Country & $\begin{array}{c}\text { Seen } \\
\text { doctor* }\end{array}$ & $\begin{array}{c}\text { Nocturnal } \\
\text { awakenings* }\end{array}$ & $\begin{array}{c}\text { Asthma- } \\
\text { attacks* }\end{array}$ & $\begin{array}{c}\text { Hospital- } \\
\text { izations* }\end{array}$ & $\begin{array}{c}\text { FEV1 } \\
<80 \% \text { pred }\end{array}$ \\
\hline Iceland & 33 & 25 & 98 & 2 & 8 \\
Norway & 25 & 32 & 100 & 0 & 19 \\
Sweden & 37 & 33 & 72 & 4 & 10 \\
Ireland & 49 & 41 & 93 & 8 & 14 \\
UK & 53 & 44 & 100 & 2 & 23 \\
Germany & 50 & 24 & 44 & 3 & 19 \\
Netherlands & 54 & 42 & 100 & 2 & 16 \\
Belgium & 60 & 45 & 100 & 8 & 17 \\
France & 37 & 43 & 100 & 2 & 16 \\
Spain & 37 & 52 & 100 & 7 & 16 \\
Italy & 38 & 40 & 77 & 0 & 9 \\
USA & 32 & 27 & 100 & 2 & 10 \\
New Zealand & 49 & 45 & 97 & 4 & 15 \\
Australia & 48 & 39 & 99 & 1 & 19 \\
\hline
\end{tabular}

*: in the last 12 months. FEV1: forced expiratory volume in one second; pred: predicted.

reported by less than half of the asthmatic subjects (table 5). A significant positive correlation was found between the proportion of subjects that had seen a doctor and the reported use of inhaled anti-inflammatory medication in the last 12 months $(\mathrm{r}=0.66, \mathrm{p}<0.05)$.

A significant positive correlation was found between prevalence of nocturnal awakenings with attacks of breathlessness and use of oral corticosteroids ( $\mathrm{r}=0.69$, $\mathrm{p}<0.01)$. There was a positive correlation between nocturnal awakenings and the ratio between reported use of inhaled anti-inflammatory and bronchodilator medication in the last 12 months $(\mathrm{r}=0.61, \mathrm{p}<0.05)$. The ratio of inhaled anti-inflammatory and bronchodilator treatment was also positively related to the prevalence of bronchial obstruction (FEV $1<80 \%$ predicted) $(\mathrm{r}=0.60, \mathrm{p}<0.05)$. No significant correlation was found between the prevalence of use of inhaled bronchodilators or anti-inflammatory medication and the prevalences of asthma attacks or hospitalization because of breathing problems.

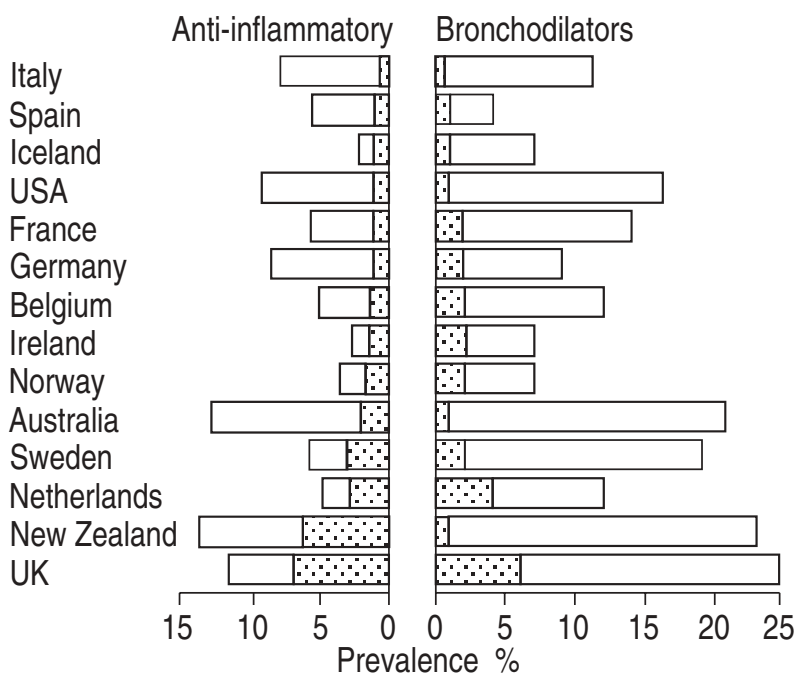

Fig. 4. - Prevalence of use of inhaled bronchodilators and inhaled anti-inflammatory medication in subjects with asthma-related symptoms. The countries are sorted by the prevalence of daily use of antiinflammatory medication. $\square$ : daily medication; $\square$ : medication in the last 12 months.
Medication in subjects with asthma-related symptoms

The highest prevalences of use of antiasthma medication in subjects with asthma-related symptoms were found in Australia (29\%), New Zealand (27\%) and the UK (27\%), while the lowest prevalences were found in Spain (9\%), Iceland $(8 \%)$ and Norway (8\%). The highest prevalences of inhaled anti-inflammatory medication were found in New Zealand (14\%) and Australia (13\%), while the lowest prevalences were seen in Norway $(3 \%)$, Ireland (3\%) and Iceland (2\%) (fig. 4). The highest use of inhaled bronchodilators in the last 12 months was found in the UK (25\%) and New Zealand $(23 \%)$, while the lowest prevalence was seen in Norway $(7 \%)$ Iceland $(7 \%)$, and Spain (4\%) (fig. 4). The geographical variations in the prevalences of use of antiasthmatic medication were all statistically significant $(p<0.001)$.

\section{Discussion}

The main finding of this analysis is the wide geographical variation in the prevalence of physician-diagnosed asthma and the use of antiasthma medication. The prevalence of physician-diagnosed asthma and antiasthma medication was higher in the centres of New Zealand and Australia than in any of the European centres. The highest prevalence of diagnosed asthma in Europe was found in the UK and in some of the centres in France, while the lowest prevalences were reported in Erfurt in former East Germany, and in Spain.

The geographical variation in the prevalence of physician-diagnosed asthma and antiasthma medication in this investigation is in accordance with a previous report from stage 1 of the ECRHS where we found a higher prevalence of asthma symptoms and reported antiasthma medication in New Zealand and Australia than in the European centres [10]. These results were, however, based on a short screening questionnaire which did not include any questions on whether the subject had been diagnosed as having asthma and only included one question on asthma medication. Analyses of data from the structured interview in stage 2 was, therefore, needed to obtain information on the prevalence of diagnosed asthma and the pattern of treatment for asthma. The high prevalence of physician-diagnosed asthma in Melbourne and New Zealand in the present report corresponds to the higher prevalences of asthma and asthma symptoms found in children in Australia and New Zealand compared with children in Europe [13, 14]. The geographical variation of asthma also corresponds closely to the geographical variation in atopic sensitiztion which has been presented in a previous report from the ECRHS [11].

There was a close correlation between the prevalence of physician-diagnosed asthma and the use of antiasthma medication. It is possible that some of the geographical variation in drug use is explained by underdiagnosis of asthma in some countries. However, this would not explain the large differences between countries in the use 
of inhaled anti- inflammatory drugs in subjects with physician-diagnosed asthma. The highest prevalence of use of inhaled anti-inflammatory drugs by patients with diagnosed asthma was found in New Zealand, Australia and the UK. This is in accordance with the results of an international audit in 1992, where the highest proportion of respiratory specialists who used inhaled corticosteroids as first-line treatment in chronic asthma was found in these countries [6]. These two investigations both show that asthma management in New Zealand, Australia and the UK is more in accordance with current asthma management guidelines in which early introduction of inhaled anti-inflammatory drugs in asthma treatment is emphasized [7, 8].

We did not find that subjects with diagnosed asthma in countries with a high reported use of anti-inflammatory drugs had less symptoms or lung function impairment than asthmatic subjects from countries with a low utilization of anti-inflammatory drugs. On the contrary, there was a significant positive correlation between the prevalence of nocturnal attacks of breathlessness and the use of oral and inhaled anti-inflammatory treatment. This suggests that the use of anti-inflammatory drugs was highest in the countries with the highest proportion of severe asthmatics. The differences in the utilization of antiasthma drugs between countries may therefore reflect a geographical variation in asthma severity, as well as differences in adherence to international guidelines. It is, however, important to emphasize that these conclusions are only based on an ecological analysis and should be confirmed with analyses of drug utilization at the individual level.

A considerable proportion of the subjects who had used medication for asthma in the last year did not have physician-diagnosed asthma. We therefore also analysed drug utilization in subjects with asthma-related symptoms by country. With this wider asthma definition the proportion of subjects who had used medication for asthma was lower than in the population with diagnosed asthma. The highest prevalence of medication for asthma and use of inhaled anti-inflammatory drugs in subjects with asthma-related symptoms was found in Australia, New Zealand and the UK. The result of this analysis therefore showed a similar pattern to that found when analysing the geographical variation of drug treatment in subjects with diagnosed asthma

In most centres, neither physician-diagnosed asthma nor reported use of antiasthma medication was significantly associated with age or gender. There was, however, a trend towards a higher prevalence of physiciandiagnosed asthma and use of antiasthma medication in women than in men. This difference was only significant in a few of the centres and in one centre, Antwerp City, there was actually a significant male dominance of use of antiasthma treatment. There was also a trend towards decreasing prevalence of current physician-diagnosed asthma with increasing age, while no clear overall relationship between reported use of antiasthma medication and age was found in this study. It should also be noted that the number of statistically significant associations found between diagnosed asthma and reported use of antiasthma medication and age or sex were about as many as could be randomly expected given the large number of tests performed in this analysis.
The prevalence of use of alternative remedies for breathing problems was low in most centres. There were, however, some exceptions, such as Hamburg and some of the French centres, where a high prevalence of use of herbal remedies for breathing problems was reported. Two studies from the USA and Australia have highlighted that the use of alternative remedies is prevalent in the general population $[15,16]$. In the American study, the diagnosis for which the remedies had been taken was included [15]. As in our results, the use of alternative remedies was low in persons with pulmonary problems compared with other diagnostic groups.

In most countries, antiasthma drugs are only available on prescription. An interesting observation was that, even in countries where most of the individuals with diagnosed asthma were taking prescribed antiasthma medication, there was a large proportion that had not seen a doctor in the last 12 months. In a pharmacybased study from Australia, GiBson et al.[17] found that undertreated asthmatics visited their doctors less often than patients that were taking adequate treatment. The correlation found between the proportion of asthmatic subjects that had seen a doctor and the reported use of inhaled anti-inflammatory treatment in the present investigation also suggests that lack of regular medical check-ups might lead to under-usage of prophylactic asthma medication.

One problem when interpreting our data is that there was a large variation in response rate. A low response rate may lead to a considerable overestimation of the actual prevalences if there is a higher prevalence of asthma in the responders than nonresponders [18]. In order to adjust for this, symptoms in stage 1 as well as sex and age were used to calculate adjusted prevalence rates [11]. In most centres, this adjustment only slightly changed the prevalence rates. In two centres, Bordeaux and Montpellier, the adjustment did, however, result in a fairly large decrease in the prevalences of both diagnosed asthma and use of antiasthma medication. All significant relationships in our ecological analysis remained statistically significant when the analysis was repeated without these two centres. Omitting the data from Bordeaux and Montpellier would, therefore, not have changed the conclusions of this study.

One of the principal aims of this study was to estimate the geographical variation in drug utilization in asthmatic subjects. As antiasthma drugs are usually introduced after consulting a doctor, physician-diagnosed asthma was chosen as the criterion for defining asthma. In order to exclude subjects who had asthma only in childhood, we only included individuals who reported having had asthma-related symptoms in the last 12 months. When analysing the subpopulations of individuals with physician-diagnosed asthma and subjects with asthmarelated symptoms we made our comparison by country. This was necessary in order to increase the number of asthmatics in each group. It was also seen as a method of detecting national differences in the use of antiasthmatics. These results must, however, be interpreted cautiously as the centres were not selected to be representative of the countries and in several countries we had only one centre. A further limitation is that this approach does not take into account that there is an important variability between centres within individual countries. 
We conclude that there is a wide geographical variation in the prevalence of physician-diagnosed asthma with the highest prevalences found in New Zealand and Australia and the lowest in Erfurt in former East Germany and in Spain. There is a close correlation between the prevalence of physician-diagnosed asthma and the overall use of antiasthma medication. The geographical variation in the use of anti-inflammatory drugs among individuals with diagnosed asthma may be related to variations in asthma severity, as well as differences in treatment practices between countries.

Acknowledgements: The co-ordination of this work was supported by the European Commission and we are grateful to the late C. Baya and M. Hallen for their help during the study and to K. Vuylsteek and the members of the COMAC for their support. The following grants helped to fund the local studies: Australia: Allen and Hanbury's, Australia; Belgium: Belgian Science Policy Office, National Fund for Scientific Research; France: Ministère de la Santé, Glaxo France, Institut Pneumologique d'Aquitaine, Contrat de Plan Etat-Région Languedoc-Rousillon. CNMATS, CNMRT (90MR/10, 91AF/6), Ministre delegué de la santé, RNSP; Germany: GSF, and the Bundesminister für Forschung und Technologie, Bonn; Greece: The Greek Secretary Genera of Research and Technology, Fisons, Astra and BoehringerIngelheim; Italy: Ministero dell'Università e della Ricerca Scientifica e Tecnologica, CNR, Regione Veneto grant RSF n. 381/05.93; New Zealand: Asthma Foundation of New Zealand, Lotteries Grant Board, Health Research Council of New Zealand; Norway: Norwegian Research Council project no. 101422/310; Portugal: Glaxo Farmacêutica Lda, Sandoz Portugesa; Spain: Ministero Sanidad y Consumo FIS grants \#91/0016060/00E-05E., \#92/0319, \#93/0393, Hospital General de Albacete, Hospital General Juan Ramón Jiménenz, Consejeria de Sanidad Principado de Asturias; Sweden: The Swedish Medical Research Council, the Swedish Heart Lung Foundation, the Swedish Association against Asthma and Allergy, The Swedish Society of Medicine, Astra, Glaxo-Wellcome, Boehringer-Ingelheim; Switzerland: Swiss National Science Foundation grant 4026-28099; UK: National Asthma Campaign, British Lung Foundation, Dept of Health, South Thames Regional Health Authority; USA: United States Dept of Health, Education and Welfare Public Health Service Grant \#2 S07 RR05521-28.

\section{List of principal participants}

Co-ordinating Centre (London): P. Burney, S. Chinn, C. Luczynska, D. Jarvis, E. Lai.

Project Management Group: P. Burney (Project leader), S. Chinn, C. Luczynska, D. Jarvis, P. Vermeire (Antwerp), J. Bousquet (Montpellier), D. Nowak (Hamburg), J. Prichard (Dublin), R. de Marco (Verona), B. Rijcken (Groningen), J. Anto (Barcelona), J. Alves (Oporto), G. Boman (Uppsala), H. Kesteloot (Leuven), N. Nielsen (Copenhagen), P. Paoletti (Pisa).

Participating centres: Austria: W. Popp (Vienna); Australia: M Abramson, J. Kutin (Melbourne); Belgium: P. Vermeire, F. van Bastelaer (Antwerp South, Antwerp Central); Estonia: R. Jögi (Tartu); France: J. Bousquet (Montpellier), F. Neukirch, R. Liard (Paris), I. Pin, C. Pison (Grenoble), A. Taytard (Bordeaux); Germany: H. Magnussen, D. Nowak (Hamburg), H.E. Wichmann, J. Heinrich (Erfurt); Greece: N. Papageorgiou, P. Avarlis, M. Gaga, C. Marossis (Athens); Iceland: T. Gislason, D. Gislason, (Reykjavik); Ireland: J. Prichard, S. Allwright, D. MacLeod (Dublin); Italy: M. Bugiani, C. Bucca, C. Romano (Turin), R. de Marco, V. Lo Cascio, C. Campello (Verona), A. Marinoni, I. Cerveri, L. Casali (Pavia); Netherlands: B. Rijcken, A. Kremer (Groningen, Bergenop-Zoom, Geleen); New Zealand: J. Crane, S. Lewis (Wellington, Christchurch, Hawkes Bay); Norway: A. Gulsvik, E. Omenaas (Bergen); Portugal: C. Loureiro, C. Chieira, R. Cordeiro (Coimbra), J.A. Marques, J. Alves (Oporto); Spain: J. Anto, J. Castellsague, J. Sunyer, J. Soriano, M. Galobardes, J. Roca, A. Tobias (Barcelona), N. Muniozguren, J. Ramos González, A. Capelastegui (Galdakao), J. Castillo, J. Rodriguez Portal (Seville), J. Martinez-Moratalla, E.
Almar (Albacete), J. Maldonado Pérez, A Pereira, J. Sánchez (Huelva), J. Quiros, I. Huerta (Oviedo); Sweden: G. Boman, C. Janson, E. Björnsson (Uppsala), L. Rosenhall, E. Norrman, B. Lundback (Umeå), N. Lindholm, P. Plaschke (Göteborg); Switzerland: U. Ackermann-Liebrich, N. Künzli, A. Perruchoud (Basel); UK: M. Burr, J. Layzell (Caerphilly), R. Hall (Ipswich), B. Harrison (Norwich), J. Stark (Cambridge); USA: S. Buist, W. Vollmer, M. Osborne (Portland).

\section{References}

1. Nordic Council on Medicines. Nordic statistics on Medicines 1990-1992. NLN publication No. 34, Uppsala 1993.

2. Sly RM. Changing asthma mortality and sales of inhaled bronchodilators and antiasthmatic drugs. Ann Allergy 1994; 73: 439-443.

3. Van Ganse E, Van der Linden PD, Leufkens HGM, Herings RMC, Vincken W, Ernst P. Asthma medication and disease exacerbations; an epidemiological study as a method for asthma surveillance. Eur Respir J 1995; 8: 1856-1860.

4. Vermeire PA, Wittesaele WW, Janssen E, De Backer WA. European audit of asthma therapy. Chest 1986: 90: 50s-61s.

5. Ruggieri F, Hindle M. Diagnosis and treatment of asthma across Europe. Eur Respir J 1989; 2 (Suppl. 6): 536s-539s.

6. Vermeire P. Differences in asthma management around the world. Eur Respir Rev 1994; 4: 279-281.

7. National Heart, Lung, and Blood Institute, National Institute of Health. International Consensus Report on the diagnosis and management of asthma. NIH publication number 92-3091, 1992.

8. National Institute of Health, National Heart, Lung, and Blood Institute. Global Initiative for asthma. NIH publication number 95-3659, 1995.

9. Burney PGJ, Luczynska C, Chinn S, Jarvis D. The European community respiratory health survey. Eur Respir J 1994; 7: 954-960.

10. European Community Respiratory Health Survey. The prevalence of respiratory symptoms in the European Community Respiratory Health Survey (ECRHS). Eur Respir J 1996; 9: 687-695.

11. European Community Respiratory Health Survey. The distribution of total and specific serum IgE in the European Community Respiratory Health Survey. J Allergy Clin Immunol 1997; 99: 687-695.

12. Francis B, Green M, Payne C, eds. The GLIM system release 4 manual. Oxford, Clarendon Press, 1993.

13. Pearce N, Weiland S, Keil U, et al. Self-reported prevalence of asthma symptoms in children in Australia, England, Germany and New Zealand: an international comparison using the ISAAC protocol. Eur Respir $J$ 1993; 6: 1455-1461.

14. Burr ML, Limb ES, Andrae S, Barry DMJ, Nagel F. Childhood asthma in four countries: a comparative study. Int J Epidemiol 1994: 23: 341-347.

15. Eisenberg DM, Kessler RC, Foster C, Norlock FE, Calkins DR, Delbanco TL. Unconventional medicine in the United States. Prevalence, costs, and patterns of use. $N$ Engl J Med 1993; 328: 246-252.

16. MacLennan AH, Wilson DH, Taylor A. Prevalence and cost of alternative medicine in Australia. Lancet 1996; 347: $569-573$.

17. Gibson P, Henry D, Francis L, et al. Association between availability of nonprescription beta -agonist $_{2}$ inhalers and undertreatment of asthma. Br Med J 1993; 306: 1514-1518.

18. De Marco R, Verlato G, Zanolin E, Bugiani M, Drane JW. Nonresponse bias in EC Respiratory Health Survey in Italy. Eur Respir J 1994; 7: 2139-2145. 